\title{
Baseline central macular thickness predicts the need for retreatment with intravitreal triamcinolone plus laser photocoagulation for diabetic macular edema
}

\author{
This article was published in the following Dove Press journal: \\ Clinical Ophthalmology \\ I August 2013 \\ Number of times this article has been viewed
}

\author{
Roderick O'Day' \\ Daniel Barthelmes' \\ Meidong Zhu' \\ Tien Yin Wong ${ }^{2,3}$ \\ lan L McAllister ${ }^{4}$ \\ Jennifer J Arnold ${ }^{5}$ \\ Mark C Gillies' \\ 'Clinical Ophthalmology and Eye \\ Health, The University of Sydney, \\ Sydney, NSW, Australia; ${ }^{2}$ Singapore \\ Eye Research Institute, National \\ University of Singapore, Singapore; \\ ${ }^{3}$ Center for Eye Research Australia, \\ The University of Melbourne, \\ Melbourne, VIC, Australia; ${ }^{4}$ Lions Eye \\ Institute, The University of Western \\ Australia, Perth, WA, Australia; \\ ${ }^{5}$ Marsden Eye Specialists, Sydney, \\ NSW, Australia
}

Purpose: To identify baseline characteristics that predict the number of treatments with intravitreal triamcinolone acetonide (IVTA) plus laser photocoagulation needed to treat diabetic macular edema over a 2-year period.

Methods: Individual data from 42 eyes of 42 participants treated with IVTA plus laser photocoagulation for diabetic macular edema during a prospective, randomized, double-masked, placebo-controlled trial were used for this post hoc analysis. Baseline characteristics - age, gender, best-corrected visual acuity, glycosylated hemoglobin, phakic status, intraocular pressure, and central macular thickness (CMT) - were correlated with the number of IVTA plus laser treatments received during the 2 years of this study.

Results: The median number of treatments received over the 2-year period was 2.5 (interquartile range 1.0-3.0), with $21(50 \%)$ eyes needing three or more treatments. Eyes that received more IVTA plus laser treatments had a higher mean baseline CMT and eyes with a higher baseline CMT were more likely to receive three or more treatments (odds ratio 5.13, 95\% confidence interval $1.75-15.04, P=0.003$ per $100 \mu \mathrm{m}$ increase in CMT). No significant relationship was found between other baseline characteristics and the number of IVTA plus laser treatments received.

Conclusion: Higher baseline CMT was strongly linked with receiving more IVTA plus laser treatments. These patients may be at higher risk of developing dose-dependent steroid-related adverse events, cataract progression, and intraocular pressure rise.

Keywords: diabetic macular edema, intravitreal triamcinolone, central macular thickness

\section{Introduction}

Diabetic retinopathy is the leading cause of blindness in working-age persons around the world. ${ }^{1,2}$ It can be found in three out of four patients within 15 years of the diagnosis of diabetes. ${ }^{3,4}$ Visual impairment is most commonly a consequence of diabetic macular edema (DME). ${ }^{5,6}$ While vascular endothelial growth factor inhibitors are usually used first for DME, intravitreal triamcinolone acetonide monotherapy (IVTA) has also been proven to be efficacious for refractory DME and vision loss in eyes that fail laser therapy. ${ }^{1,7}$ It has been shown to improve vision and reduce central macular thickness (CMT), with benefits persisting for up to 5 years. ${ }^{8-10}$ Moreover, for patients with earlier DME, IVTA followed by laser photocoagulation has been shown to double the chance of an improvement in vision by ten or more best-corrected logarithm of minimum angle of resolution letters at 2 years compared to laser alone. ${ }^{11}$ This result
Correspondence: Roderick FJ O’Day Clinical Ophthalmology and Eye Health, The University of Sydney,

Sydney Hospital, 8 Macquarie Street, Sydney, NSW 2000, Australia

Tel +6I 42I 434454

Email roderick.oday@gmail.com 
can be contrasted with the Diabetic Retinopathy Clinical Research Network trial, which found that only the subset of eyes that were pseudophakic at baseline had better visual acuity outcomes after IVTA combined with prompt laser treatment. ${ }^{12}$ The divergent findings may in part be due to differences in study protocol, ie, the shorter period of time between IVTA and laser therapy in the Diabetic Retinopathy Clinical Research Network study (3-10 days versus 6 weeks) may not have allowed sufficient time for the edema to resolve before application of the laser. ${ }^{11,12}$

Since patients often require more than one injection with IVTA, they may be at higher risk of dose-dependent steroid-related adverse events, principally cataract and raised intraocular pressure (IOP). ${ }^{13-15}$ This paper examines whether it is possible to predict from baseline characteristics the number of IVTA injections patients will require once they embark on a course of combined therapy with laser photocoagulation.

\section{Materials and methods}

This analysis was based on data from the THUNDERBIRD (A Multicenter Randomized Clinical Trial of Laser Treatment Plus IVTA for DME) study, a prospective, randomized, double-masked, placebo-controlled trial. ${ }^{11,16}$ The THUNDERBIRD study tested the hypothesis that there is a synergistic effect of IVTA and laser photocoagulation on vision improvement and reduction in macular thickness in eyes with DME. The study was conducted in accordance with the Declaration of Helsinki and was approved by the Research Ethics Committees of the four participating clinical centers. Patients were included in the THUNDERBIRD study if they had focal or diffuse DME involving the central fovea with a CMT of greater than $250 \mu \mathrm{m}$ and best-corrected logarithm of minimum angle of resolution letters read (ie, best-corrected visual acuity [BCVA]) in the affected eye(s) of 17-70 letters. Time-domain optical coherence tomography was performed (Stratus OCT ${ }^{\mathbf{M}}$; Carl Zeiss Meditec, Jena, Germany) to determine the average thickness of the central macula ( $1 \mathrm{~mm}$ diameter). Eyes were allocated either to IVTA injection or sham-injection 6 weeks prior to laser photocoagulation. Eyes assigned to IVTA received an intravitreal injection of $0.1 \mathrm{~mL}$ of Kenacort $^{\circledR} 40$ (40 mg/mL triamcinolone acetonide; BristolMyers Squibb, New York, NY, USA). Eyes assigned to placebo were prepared in the same way but had the barrel of the syringe without a needle pushed firmly against the eye to simulate an injection.
Retreatment with injection of study medication followed by laser photocoagulation was considered at the discretion of the chief investigator at each site at each visit, as long as treatments were at least 6 months apart, unless any of the following were present:

- The investigator considered the macula nearly flat and central optical coherence tomography thickness was $<300 \mu \mathrm{m}$;

- BCVA was 79 letters or better (20/25) or BCVA had improved by five letters or more compared with the best BCVA after treatment or baseline acuity; or

- Laser treatment was considered by investigator as "inappropriate" or had no potential for improvement.

Only eyes that received IVTA in these studies were included in this analysis. Further details on patient enrolment, sample size calculation, treatment assignment, data collection and masking, treatment, and outcomes can be found in previously published reports of this trial. ${ }^{11,16}$

\section{Statistical analysis}

Data are presented as the mean \pm standard deviation when normally distributed or as median (interquartile range) if not. Normality was assessed using the Shapiro-Wilk test.

The analysis of the factors predictive of the extent of IVTA plus laser treatment was not a prospectively defined outcome of the study. There was a potential maximum of five treatments per participant over the 2 years. Eyes were analyzed according to the number of treatments they received: one versus two versus three versus four or five. For the purposes of a binary logistic regression analysis, eyes were classified as having either received few (one or two) or many (three or more) treatments.

Differences in continuous variables between multiple groups were compared using an analysis of variance or the Kruskal-Wallis test for normally and not normally distributed data, respectively. In cases of significant analysis of variance results, post hoc testing was performed. If equal variances could be assumed, a Bonferroni correction was applied. If not, Dunn's test was applied. The homogeneity of variances was assessed using Levene's test. Differences in proportions between multiple groups were analyzed using the chi-squared test.

The measured baseline characteristics were age, gender, BCVA, glycosylated hemoglobin $\left(\mathrm{HbA}_{1 \mathrm{c}}\right)$, phakic status, IOP, and CMT.

To analyze the predictive value of baseline characteristics on the number of treatments received, binary logistic 
regression and multinomial logistic regression models were applied. Eyes with missing values were excluded from these analyses. For these, the dependent variable was the number of treatments received, classified as described above. The independent variables were the baseline characteristics. Gender (female = reference category) and phakia (pseudophakic $=$ reference category) were defined as categorical variables. All other independent variables were defined as continuous variables. For the regression analyses, baseline CMT was divided by 100 . The resulting odds ratios were per $100 \mu \mathrm{m}$ difference in baseline CMT. Since the a priori risk of retreatment was not known, a Cox regression was performed in addition to the logistic regression analyses.

An a priori $P$-value of $<0.05$ was defined as statistically significant. All data were analyzed using a commercially available software package (SPSS ${ }^{\circledR} 21$; IBM Corporation, Armonk, NY, USA).

\section{Results}

Of the 42 eyes treated with IVTA plus laser photocoagulation in the THUNDERBIRD study, 14 (33\%) were pseudophakic at baseline and $16(38 \%)$ patients were female. The mean age at baseline was $66.8 \pm 10.4$ years, IOP was $16.1 \pm 3.0 \mathrm{mmHg}$, and CMT was $482 \pm 123 \mu \mathrm{m}$. The median baseline BCVA was 57 (53-70) letters and $\mathrm{HbA}_{1 \mathrm{c}}$ was 7.6\% (7.2\%-9.4\%). Data for the measured baseline characteristics were complete, except for one eye with no recorded $\mathrm{HbA}_{1 \mathrm{c}}$ value.

A total of 101 IVTA plus laser treatments were given during the 2 years of this study. The median number of treatments was 2.5 (1.0-3.0). Only one treatment was required in eleven (26\%) eyes, two in ten (24\%) eyes, three in $14(33 \%)$ eyes, four in seven $(17 \%)$ eyes, and five in zero $(0 \%)$ eyes.

\section{Characteristics of patients and visual outcomes in eyes treated with IVTA plus laser}

Eyes that received more IVTA plus laser treatments had significantly thicker maculas at baseline (Table 1 and Figure 1). There were no other statistically significant differences in measured baseline characteristics between eyes classified on the basis of number of treatments they received.

\section{Predicting number of IVTA plus laser treatments}

A total of 41 eyes (98\%) had complete data. Increased baseline CMT was found to be a significant predictor of receiving three or more treatments in the binary logistic regression model (odds ratio 5.13, 95\% confidence interval 1.75-15.04, $P=0.003$ per $100 \mu \mathrm{m}$ increase in CMT) (Table 2). Cox regression analysis produced a result in the same range as the binary logistic regression model. Similarly, a high baseline CMT was significantly associated with an increased risk of receiving three and four, but not two, treatments in the multinomial logistic regression model (Table 3). Age, gender, baseline BCVA, baseline $\mathrm{HbA}_{1 \mathrm{c}}$, baseline phakia and baseline IOP were not predictive of the number of IVTA plus laser treatments received.

\section{Discussion}

In this post hoc analysis of data from a prospective, randomized, double-masked, placebo-controlled clinical trial of eyes with DME, increasing baseline CMT was strongly linked with requiring more IVTA plus laser treatments. ${ }^{11,16}$ Eyes that eventually received more IVTA plus laser during the 2 years of this study had significantly greater mean baseline CMT. In binary and multinomial logistic

Table I Baseline characteristics and visual outcomes of eyes treated with intravitreal triamcinolone acetonide stratified with respect to number of intravitreal triamcinolone acetonide plus laser treatments received

\begin{tabular}{|c|c|c|c|c|c|}
\hline & $\begin{array}{l}\text { One treatment } \\
(n=I I)\end{array}$ & $\begin{array}{l}\text { Two treatments } \\
(n=10)\end{array}$ & $\begin{array}{l}\text { Three treatments } \\
(n=14)\end{array}$ & $\begin{array}{l}\text { Four treatments } \\
(n=7)\end{array}$ & $P$-value \\
\hline \multicolumn{6}{|l|}{ Baseline characteristics } \\
\hline Age, years & $64.8 \pm 9.3$ & $69.3 \pm 15.5$ & $67.4 \pm 8.5$ & $65.1 \pm 7.5$ & 0.765 \\
\hline Female gender, n (\%) & $4(37 \%)$ & $4(40 \%)$ & $7(50 \%)$ & I (I4\%) & 0.466 \\
\hline$B C V A, \log M A R$ letters read & $59.0 \pm 9.2$ & $55.7 \pm 15.0$ & $50.4 \pm 13.7$ & $58.3 \pm 9.7$ & 0.333 \\
\hline $\mathrm{HbA}_{\mathrm{Ic}}, \%^{\dagger}$ & $7.1(6.3-8.88)$ & $7.6(7.1-7.9)$ & $7.9(6.6-9.4)$ & $8.4(6.6-9.3)$ & 0.646 \\
\hline Pseudophakic, n (\%) & $3(27 \%)$ & $4(40 \%)$ & $6(43 \%)$ & I (I4\%) & 0.553 \\
\hline IOP, $\mathrm{mmHg}$ & $16.0(16.0-18.0)$ & $18.5(|2.0-2| .0)$ & $15.0(14.0-16.0)$ & $16.0(14.0-18.0)$ & 0.443 \\
\hline $\mathrm{CMT}, \mu \mathrm{m}$ & $387 \pm 87$ & $438 \pm 102$ & $554 \pm 114$ & $552 \pm 95$ & 0.001 \\
\hline
\end{tabular}

Notes: ${ }^{t} \mathrm{n}=\mathrm{I}$ | for one treatment, $\mathrm{n}=9$ for two treatments, $\mathrm{n}=14$ for three treatments, and $\mathrm{n}=7$ for four treatments. Values represent mean \pm standard deviation or median (interquartile range).

Abbreviations: BCVA, best corrected visual acuity; CMT, central macular thickness; $\mathrm{HbA}_{\mathrm{Ic}}$, glycosylated hemoglobin; IOP, intraocular pressure; logMAR, Logarithm of the Minimum Angle of Resolution. 


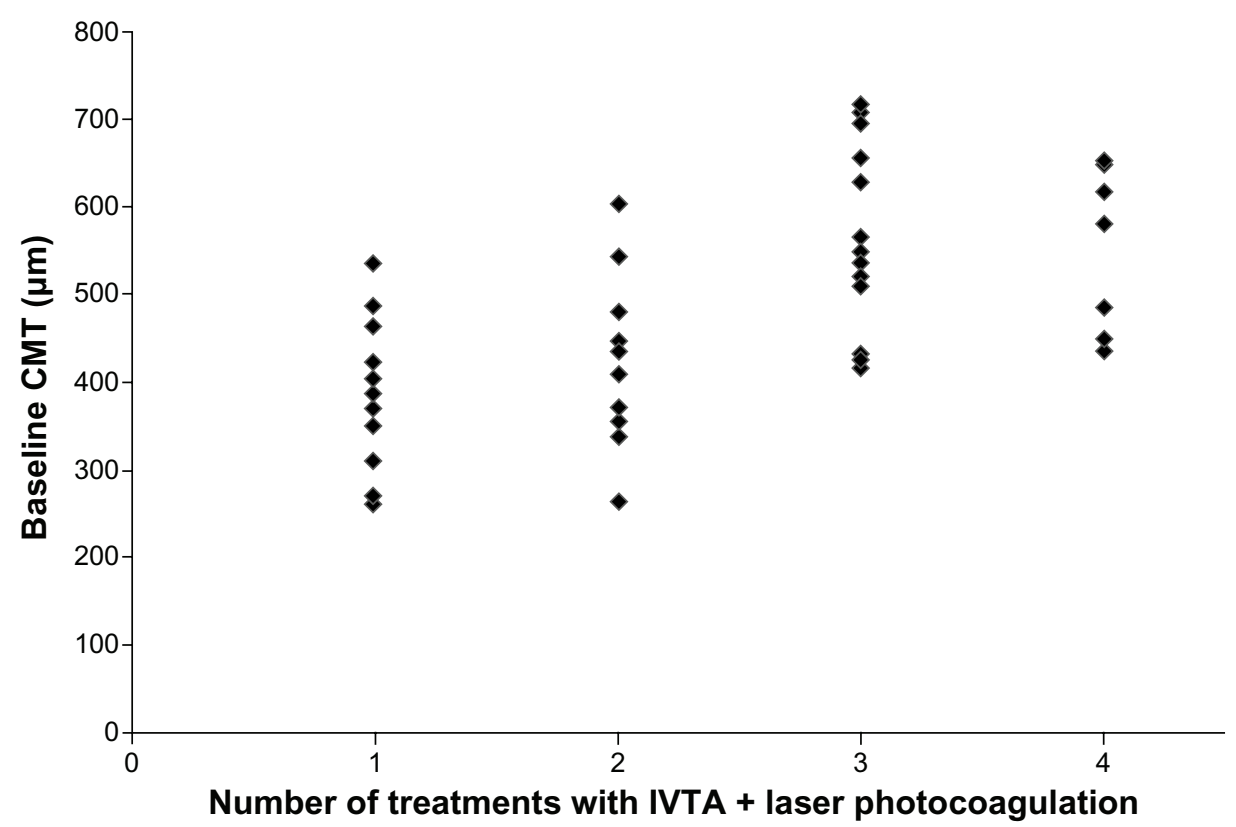

Figure I Baseline CMT stratified with respect to number of IVTA injections combined with laser photocoagulation treatments received. Abbreviations: CMT, central macular thickness; IVTA, intravitreal triamcinolone acetonide.

regression analyses, baseline CMT was associated with receiving three or more treatments. No relationship was found between other baseline characteristics (BCVA, age, gender, $\mathrm{HbA}_{1 \mathrm{c}}$, phakia, and IOP) and the number of treatments received. Notably, baseline BCVA was not a predictor of the number of treatments received.

The authors believe that the strong relationship found between a high baseline CMT and the need for IVTA retreatment in the patients participating in the THUNDERBIRD study is representative of the routine clinical use of this drug. While the data were derived from a randomized controlled trial during which loss to follow up was low, the patients in the study that received a greater number of treatments did

Table 2 Predictors of receiving at least two versus at least three intravitreal triamcinolone acetonide plus laser treatments using binary logistic regression analysis

\begin{tabular}{llll}
\hline Covariates & $\begin{array}{l}\text { Odds } \\
\text { ratio }\end{array}$ & $\begin{array}{l}\text { 95\% confidence } \\
\text { interval }\end{array}$ & P-value \\
\hline Baseline age & 1.00 & $0.92-1.09$ & 1.000 \\
Gender & 0.79 & $0.13-4.85$ & 0.800 \\
Baseline BCVA & 1.01 & $0.93-1.10$ & 0.787 \\
Baseline HbA & 0.95 & $0.49-1.85$ & 0.884 \\
Baseline phakia & 2.90 & $0.43-19.74$ & 0.277 \\
Baseline IOP & 0.87 & $0.65-1.15$ & 0.316 \\
Baseline $\mathrm{CMT}^{\dagger}$ & 5.13 & $1.75-15.04$ & 0.003 \\
\hline
\end{tabular}

Notes: 'Baseline CMT was divided by 100 ; odds ratios are per $100 \mu \mathrm{m}$ change in CMT.

Abbreviations: BCVA, best corrected visual acuity; CMT, central macular thickness; $\mathrm{HbA}_{\mathrm{Ic}}$, glycosylated hemoglobin; IOP, intraocular pressure. so because they met the retreatment criteria more frequently. These criteria were similar to those used in clinical practice, in which treatment is given at the clinician's discretion in light of findings from clinical examination and imaging. If a clinician has a patient similar to those included in this study and applies similar retreatment criteria, then baseline CMT can be used to predict how many treatments will be prescribed.

This analysis is not equipped to determine why the eyes in this study with thicker maculas at baseline received more treatments than eyes with less swollen maculas. It can be inferred from the prospectively defined criteria that eyes that received multiple treatments were not responding as well to therapy. In this study, eyes were considered for reinjection plus laser 6 weeks later unless macular edema resolved, BCVA improved, or laser photocoagulation was no longer considered appropriate.

There are many potential reasons why eyes with higher baseline CMT might require more treatment. It might be that eyes with more fluid require more therapy to dry out the macula, ie, a high CMT is representative of more severe retinal dysfunction which requires more treatments to stabilize. ${ }^{17}$ Alternatively, in contrast to previous reports, it may be that DME is more likely to recur in eyes with a high baseline CMT. ${ }^{18}$ Irrespective of the mechanisms underlying the current findings, the ability to predict which patients will require multiple treatments has important implications for the risk and benefit profile of treatment. The main side 
Table 3 Predictors of receiving two, three, or four intravitreal triamcinolone acetonide plus laser treatments compared to receiving one treatment using multinomial logistic regression analysis

\begin{tabular}{|c|c|c|c|c|c|c|}
\hline & Two treatments & $P$-value & Three treatments & $P$-value & Four treatments & $P$-value \\
\hline \multicolumn{7}{|l|}{ Baseline characteristics } \\
\hline Age & $1.03(0.93-1.15)$ & 0.578 & I.0I (0.90-I.I2) & 0.933 & $\mathrm{I} .05(0.89-1.23)$ & 0.570 \\
\hline Female gender & $0.88(0.09-8.42)$ & 0.909 & $1.86(0.20-17.67)$ & 0.590 & $0.25(0.01-5.97)$ & 0.391 \\
\hline BCVA & $0.98(0.88-1.08)$ & 0.638 & $0.97(0.87-1.08)$ & 0.567 & $\mathrm{I} .06(0.94-1.2 \mathrm{I})$ & 0.354 \\
\hline $\mathrm{HbA}_{\mathrm{lc}}$ & I. $17(0.54-2.52)$ & 0.690 & $0.99(0.44-2.22)$ & 0.976 & I.II (0.43-2.86) & 0.833 \\
\hline Pseudophakic, yes or no & $2.6 \mathrm{I}(0.20-34.60)$ & 0.466 & $1.00(0.08-13.23)$ & 0.999 & $0.14(0.00-4.66)$ & 0.272 \\
\hline IOP & $1.17(0.83-1.65)$ & 0.385 & $0.94(0.64-1.37)$ & 0.752 & $0.9 I(0.58-1.4 I)$ & 0.667 \\
\hline $\mathrm{CMT}^{\dagger}$ & I.3। (0.38-4.45) & 0.669 & $5.46(1.45-20.57)$ & 0.012 & $8.02(I .63-39.4 I)$ & 0.010 \\
\hline
\end{tabular}

Notes: ${ }^{\dagger}$ Baseline CMT was divided by 100 ; odd ratios are per $100 \mu \mathrm{m}$ change in CMT. Values represent the odds ratio ( $95 \%$ confidence interval).

Abbreviations: BCVA, best corrected visual acuity; CMT, central macular thickness; $\mathrm{HbA}_{\mathrm{lc}}$, glycosylated hemoglobin; IOP, intraocular pressure.

effects of IVTA treatment are IOP elevation and accelerated cataract formation, both of which are dose dependent. The risk of cataract formation and subsequent cataract surgery is strongly dose related. ${ }^{13,19-21}$ Similarly, it has been shown that the duration of ocular hypertension is longer with higher doses of IVTA. ${ }^{14}$ The benefits to be gained from treatment in eyes with high baseline CMT should be balanced with the greater risk of developing adverse events.

The major weakness of this retrospective analysis is the relatively small number of patients available for analysis. A weaker correlation than that found for baseline CMT may therefore have been missed. Conversely, the strength of the relationship between CMT and the number of IVTA plus laser treatments received should be viewed positively in light of the number of patients analyzed. The need for retreatment was not a prospectively defined outcome and the reasons for a decision to retreat or not were not collected from the investigators. Future trials should assess these factors as the ability to predict the number of intravitreal therapies that will be required before embarking on a course of therapy would be highly beneficial to patient care. This would be equally applicable to vascular endothelial growth factor inhibitors, whose treatment regimen is more intense with less time between injections than that of IVTA.

\section{Conclusion}

In summary, this analysis assessed the predictive value of baseline characteristics of the number of IVTA plus laser treatments needed to control DME in the first 2 years of a clinical trial. A high baseline CMT was shown to be strongly associated with receiving more IVTA plus laser treatments. No relationships were found with other commonly measured baseline characteristics. The practical implication of the findings of this study is that baseline CMT may be used as a factor when weighing up the risks and benefits of IVTA treatment for DME. This may become an important measure in the clinical decision making of the treatment of this disease.

\section{Acknowledgments}

The THUNDERBIRD study was investigator initiated and unsupported by the pharmaceutical industry. It was funded from the following grant: NHMRC Project Grant Number 352312 (2005-2008). The Safety Monitoring Committee comprised: Jeremy Smith, Paul Power, and Jie Jin Wang.

\section{Disclosure}

The authors report no conflicts of interest in this work.

\section{References}

1. Cheung N, Mitchell P, Wong TY. Diabetic retinopathy. Lancet. 2010;376(9735):124-136.

2. Kempen JH, O'Colmain BJ, Leske MC, et al. The prevalence of diabetic retinopathy among adults in the United States. Arch Ophthalmol. 2004;122(4):552-563.

3. Klein R, Klein BE, Moss SE, Davis MD, DeMets DL. The Wisconsin epidemiologic study of diabetic retinopathy II. Prevalence and risk of diabetic retinopathy when age at diagnosis is less than 30 years. Arch Ophthalmol. 1984;102(4):520-526.

4. Sjolie AK, Stephenson J, Aldington S, et al. Retinopathy and vision loss in insulin-dependent diabetes in Europe. The EURODIAB IDDM Complications Study. Ophthalmology. 1997;104(2):252-260.

5. Kohner EM. Diabetic retinopathy. Clin Endocrinol Metab. 1977;6(2): 345-375.

6. Zimmet P, Alberti KG, Shaw J. Global and societal implications of the diabetes epidemic. Nature. 2001;414(6865):782-787.

7. Mohamed Q, Gillies MC, Wong TY. Management of diabetic retinopathy: a systematic review. JAMA. 2007;298(8):902-916.

8. Sutter FK, Simpson JM, Gillies MC. Intravitreal triamcinolone for diabetic macular edema that persists after laser treatment: three-month efficacy and safety results of a prospective, randomized, double-masked, placebo-controlled clinical trial. Ophthalmology. 2004;111(11): 2044-2049.

9. Gillies MC, Sutter FK, Simpson JM, Larsson J, Ali H, Zhu M. Intravitreal triamcinolone for refractory diabetic macular edema: two-year results of a double-masked, placebo-controlled, randomized clinical trial. Ophthalmology. 2006;113(9):1533-1538. 
10. Gillies MC, Simpson JM, Gaston C, et al. Five-year results of a randomized clinical trial with open-label extension of intravitreal triamcinolone for refractory diabetic macular edema. Ophthalmology. 2009;116(11):2182-2187.

11. Gillies MC, McAllister IL, Zhu M, et al. Intravitreal triamcinolone prior to laser treatment of diabetic macular edema: 24-month results of a randomized controlled trial. Ophthalmology. 2011;118(5):866-872.

12. Elman MJ, Aiello LP, Beck RW, et al; Diabetic Retinopathy Clinical Research Network. Randomized trial evaluating ranibizumab plus prompt or deferred laser or triamcinolone plus prompt laser for diabetic macular edema. Ophthalmology. 2010;117(6):1064-1077.

13. Gillies MC, Islam FM, Zhu M, Larsson J, Wong TY. Efficacy and safety of multiple intravitreal triamcinoloone injections for refractory diabetic macular oedema. Br J Ophthalmol. 2007;91(10):1323-1326.

14. Jonas JB, Degenring RF, Kreissig I, Akkoyun I, Kamppeter BA. Intraocular pressure elevation after intravitreal triamcinolone acetonide injection. Ophthalmology. 2005;112(4):593-598.

15. Gillies MC, Kuzniarz M, Craig J, Ball M, Luo W, Simpson JM. Intravitreal triamcinolone-induced elevated intraocular pressure is associated with the development of posterior subcapsular cataract. Ophthalmology. 2005;112(1):139-143.
16. Gillies MC, McAllister IL, Zhu M, et al. Pretreatment with intravitreal triamcinolone before laser for diabetic macular edema: 6-month results of a randomized, placebo-controlled trial. Invest Ophthalmol Vis Sci. 2010;51(5):2322-2328.

17. Sanchez-Tocino H,Alvarez-VidalA, Maldonado MJ, Moreno-Montanes J, Garcia-Layana A. Retinal thickness study with optical coherence tomography in patients with diabetes. Invest Ophthalmol Vis Sci. 2002;43(5): 1588-1594.

18. Mohamed S, Leung GM, Chan CK, et al. Factors associated with variability in response of diabetic macular oedema after intravitreal triamcinolone. Clin Experiment Ophthalmol. 2009;37(6):602-608.

19. Gillies MC, Simpson JM, Billson FA, et al. Safety of an intravitreal injection of triamcinolone: results from a randomized clinical trial. Arch Ophthalmol. 2004;122(3):336-340.

20. Konstantopoulos A, Williams CP, Newsom RS, Luff AJ. Ocular morbidity associated with intravitreal triamcinolone acetonide. Eye (Lond). 2007;21(3):317-320.

21. Gillies MC, Islam FM, Larsson J, et al. Triamcinolone-induced cataract in eyes with diabetic macular oedema: 3-year prosepective data from a randomized clinical trial. Clin Experiment Ophthalmol. 2010;38(6):605-612.
Clinical Ophthalmology

\section{Publish your work in this journal}

Clinical Ophthalmology is an international, peer-reviewed journal covering all subspecialties within ophthalmology. Key topics include: Optometry; Visual science; Pharmacology and drug therapy in eye diseases; Basic Sciences; Primary and Secondary eye care; Patient Safety and Quality of Care Improvements. This journal is indexed on

\section{Dovepress}

PubMed Central and CAS, and is the official journal of The Society of Clinical Ophthalmology (SCO). The manuscript management system is completely online and includes a very quick and fair peer-review system, which is all easy to use. Visit http://www.dovepress.com/ testimonials.php to read real quotes from published authors. 